\title{
The predictive value of impulse oscillometry for asthma exacerbations in childhood: a systematic review and meta-analyses
}

\author{
Yongsheng $\mathrm{Xu}^{1}$, Yaoyao Ling ${ }^{2}$, Yufan $\mathrm{Niu}^{2}$, and Yuqi $\mathrm{Han}^{2}$ \\ ${ }^{1}$ Tianjin Children's Hospital \\ ${ }^{2}$ Tianjin Medical University
}

August 6, 2020

\begin{abstract}
Background: Several studies have explored the predictive value of impulse oscillometry (IOS) for asthma exacerbations in childhood, but its specific parameters are still unclear. Therefore, we designed this meta-analysis to determine the related indicators of acute asthma attacks. Methods: A comprehensive literature search was performed in July 2020 based on Pubmed, Embase, and Web of science database. Weighted mean differences (WMD) were calculated using Fixed-or random-effects models. Results: A total of 615 patients from 6 trials were included in this analysis. IOS may be a useful tool to predict asthma exacerbations. And the results showed that R5 (WMD $=-1.21,95 \% \mathrm{CI}:-1.55$ to $-0.87, \mathrm{P}<0.001)$, Fres $(\mathrm{WMD}=$ - 1.34, 95\%CI: -2.03 to $-0.65, \mathrm{P}=0.018)$ and $\mathrm{AX}(\mathrm{WMD}=-7.35,95 \% \mathrm{CI}$ : -9.94 to $-4.76, \mathrm{P}<0.001)$ had significant correlation with asthma exacerbations. In addition, X5 may also predict the acute attack of asthma (WMD $=0.81,95 \%$ CI: 0.56 to 1.01 , $\mathrm{P}<0.001)$. Conclusion: R5, AX, Fres, and X5 may be able to identify the risk of an acute attack of asthma. Besides, our research further demonstrated that peripheral airway injury may play an important role in the acute attack of asthma.
\end{abstract}

\section{Introduction:}

Asthma is the most common chronic lower respiratory disease in childhood, characterized by airway inflammation and airway hyper-responsiveness. Most cases of childhood asthma occur before the age of 3 years, and pulmonary impairment often starts during the preschool ages. Moreover, acute exacerbations are one of the main causes of emergency department visits and may lead to long-term pulmonary impairment children ${ }^{[1-3]}$. Therefore, early diagnosis and early treatment are of great significance to achieve full control and reduce asthma exacerbations ${ }^{[4]}$. Lung function tests are a common detection method of asthma. Longitudinal monitoring of respiratory parameters is helpful to early intervention and improve prognosis.

Spirometry has traditionally been employed to evaluate lung function, considered as the gold standard ${ }^{[4]}$. However, young children may be unable to perform the test, since it requires effort dependent lung maneuvers. The effort dependent nature of the test interferes with the reproducibility of the test. Besides, spirometry may be limited when clinical conditions do not allow it to be carried out safely ${ }^{[5]}$.

For these reasons, impulse oscillometry (IOS), based on forced oscillation technique (FOT), has been noticed to measure lung function in young children(mainly over 3 years old $)^{[6]}$. Compared with spirometry, IOS is a much simpler and noninvasive technique for assessing airway impedance and responsiveness in children. It is effort-independent that can be performed in tidal breathing and requires minimal patient cooperation. Also, it can distinguish between the degree of obstruction in central and peripheral airways ${ }^{[7,8]}$. The main indicators of IOS are R5 (resistance at 5HZ), R20 (resistance at 20HZ), R5-20 (resistance at $5 \mathrm{~Hz}$ minus resistance at $20 \mathrm{~Hz}$ ), X5(reactance at $5 \mathrm{~Hz}), \mathrm{AX}($ reactance area), Fres(resonant frequency of reactance). 
In recent years, many studies have explored the predictive value of IOS for asthma exacerbations in childhood, but its specific indicators are still controversial. Therefore, we performed a systematic literature review and meta-analysis to further investigate the issue and identify potential sources of heterogeneity that might be confounders that have affected some existing conclusions.

\section{Methods}

This meta-analysis strictly followed the recommendations of the Preferred Reporting Items for Systematic Reviews and Meta-analyses Statement ${ }^{[9]}$. No ethical approval and patient consent were required for this review as all data were already published in peer-reviewed journals.

\section{1 literature search and selection criteria}

We conducted a comprehensive literature search of the PubMed, Embase, and Web of Science databases up to July 2020 with the following search algorithm: (asthma or asthmas or bronchial asthma or asthma, bronchial) and impulse oscillometry. Besides, the reference lists of retrieved articles and related reviews were examined to identify any potential relevant research. There were no language or publication date restrictions. The flow diagram was presented in Fig. 1.

The inclusion criteria were as follows: 1.study design was randomized controlled trials (RCT); 2. participants were children ([?]14 years old) with asthma exacerbations or poorly controlled asthma, which was diagnosed according to the Global Initiative for Asthma or relevant guidelines;3. participants used impulse oscillometry to evaluate lung function; 4 . outcome measures included impulse oscillometry parameters.

To ensure accuracy, two authors chose the studies independently, resolved their differences through discussion with the third author, and selected the articles to be included by consensus.

\section{2 quality assessment and data extraction}

The Newcastle-Ottawa Scale (NOS) was applied to assess the quality of included studies by two independent authors. NOS is a 9-star system, which scores observational studies on 3 dimensions: selection (4 items), comparability (1 item), and exposure/outcome (3 items). Except for comparability (2 points), 1 point will be given for each item. A score [?] of 7 was considered a high-quality article.

Two authors independently abstracted data and any discrepancy was

resolved by consensus. The following variables were collected from each study: author, publication year, country, type of study, age of baseline, sample size and number of cases, and measurements. The outcome of interest was parameters of IOS that can predict asthma exacerbations or loss of control.

\subsection{Statistical analyses}

For studies that reported separate effect size estimates of different related indicators of IOS in acute asthma attacks, we combined these risk estimates into each study, weighted by the inverse of the variance. Subgroup analyses were performed based on different parameters of IOS related to asthma exacerbations. Heterogeneity across included studies was assessed with the Cochrane $Q$ test (the level of significance was set at 0.1$)^{[10]}$. The $\mathrm{I}^{2}$ score was also used to determine the degree of heterogeneity $\left(\mathrm{I}^{2}<50 \%\right.$, no obvious heterogeneity; $\mathrm{I}^{2}>50 \%$, large or extreme heterogeneity $)^{[11]}$. Galbraith plot ${ }^{[12]}$ introduced to identify the studies that contributed to the heterogeneity and meta-analysis was performed again after removing these studies.

In the sensitivity analysis, the meta-analysis was repeated after each study was omitted. Begg's test ${ }^{[13]}$ and Egger's test ${ }^{[14]}$ were used to assess publication bias. Meta-analysis was conducted using STATA 12.0.

\section{Results}

3.1Study searches and characteristics of the included studies

The detailed process of the literature search is shown in Fig. 1. A total of 6 eligible studies ${ }^{[15-20]}$, published between 2016 and 2020, were enrolled in the present meta-analysis. The studies were conducted in the following 
geographical regions:USA( $(n=2)$, Germany $(n=1)$, Turkey $(n=1)$, China $(n=2)$. All studies used well-controlled asthma as the control group, and 4 studies also added healthy people as the control group ${ }^{[15,17,18,20]}$. Our study focused on the role of IOS in predicting asthma exacerbations or loss of control, so we did not include healthy people. The sample size ranged from 54 to 192, including 615 children with an average age of 3.6511.20 years. They were all case-control studies. All participants performed IOS. Meaningful pulse oscillation parameters varied among the trials. The quality scores of these studies were evaluated by the NOS ranging from 7 to 8 . The characteristics of all studies were summarized in Table1.

\subsection{Association between pulse oscillation parameters and asthma exacerbations}

The included six studies revealed that IOS may be able to identify the risk of acute attack or loss of control of asthma. We further analyzed the value of IOS common parameters in predicting the loss of asthma control. In terms of resistance, we found that elevated levels of R5 may indicate the risk of asthma exacerbations $(\mathrm{WMD}=-1.21,95 \% \mathrm{CI}:-1.55$ to $-0.87, \mathrm{P}<0.001)$ (Fig.2a).However, as for R20(WMD $=-0.81,95 \% \mathrm{CI}:-1.95$ to $0.32, \mathrm{P}=0.161$ ), $\mathrm{R} 5-20$ (WMD $=-0.68,95 \% \mathrm{CI}$ : -1.61 to $0.25, \mathrm{P}=0.151$ ), the results did not show a good correlation with the acute attack of asthma (Fig.2b-2c). In terms of reactance, we found X5 (WMD $=0.81$, 95\% CI: 0.56 to $1.01, \mathrm{P}<0.001$ ) were significantly related to the loss of asthma control(Fig.2d). Moreover, the Fres $(\mathrm{WMD}=-1.34,95 \% \mathrm{CI}:-2.03$ to $-0.65, \mathrm{P}=0.018)$ and $\mathrm{AX}(\mathrm{WMD}=-7.35,95 \% \mathrm{CI}:-9.94$ to $-4.76, \mathrm{P}<0.001)$ can also identify the risk of acute attack or loss of control of asthma(Fig.2e-2f).

\subsection{Sensitivity analysis and publication bias}

Sensitivity analysis confirmed that no individual study influenced the overall results. There was no evidence of publication bias in this meta-analysis indicated by Begg's funnel plot and Egger's tests (Fig3).

\section{Discussion}

To our knowledge, this is the first systematic review and meta-analysis of IOS parameters to identify the risk of acute attack or loss of control in children with asthma. Our research involved a total of 615 cases from 6 studies. We selected common IOS parameters and analyzed them. The results showed that R5, X5, AX, and Fres may better predict asthma exacerbations or loss of control.

Asthma is a common disease in pediatrics. The goal of care is to maximize the safety of treatment by achieving and maintaining the control of disease at the lowest level and dose of inhaled corticosteroids (ICS). Studies have shown that childhood asthma control is closely related to adult asthma control, lung function, and chronic obstructive pulmonary disease $(\mathrm{COPD})^{[21]}$. An acute attack of asthma refers to the sudden occurrence of symptoms such as wheezing, coughing, shortness of breath, chest tightness, or the acute exacerbation of the original symptoms, which can even lead to dyspnea, asphyxia and life-threatening. Therefore, timely and objective indicators are needed for early identification and prevention. Pulmonary ventilation function monitoring is an important means for future risk assessment of asthma, but it has certain limitations. IOS has been widely clinically studied because of its simple operation and its ability to measure the impedance of the respiratory system, which consists of reactance and resistance. Previous trials suggested that IOS may be a reliable non-invasive method to assess asthma control in children ${ }^{[22,23]}$.

Resistance can be conceptualized as the energy required for sound waves to pass through the airways and inflate the lung. R5 represents the total airway resistance. The included five trials found that R5 increased in asthma exacerbations ${ }^{[14-17,19]}$. Only Smith et al did not report the difference in R5 between the two groups $^{[17,19]}$. Our study showed that $\mathrm{R} 5$ had a good correlation with the acute attack of asthma. Besides, Galant et al held that R5 increased significantly when peripheral airway obstruction occurred ${ }^{[24]}$. The reactance of the respiratory system, expressed in Xrs, consists of the inert and elastic properties of the respiratory system. X5 is defined as the peripheral elastic resistance, providing important information about the peripheral respiratory tract. When small airway obstruction and lung compliance decrease, the negative value will increase significantly ${ }^{[25]}$. Our study found a good correlation between X5 and asthma loss of control. Schulze et al found that X5 represents hyperinflation ${ }^{[16]}$. Tirakitsoontorn et al also reported X5 may be well suited to identify peripheral airway impairment phenotype in the clinical setting ${ }^{[18]}$. Galant et 
al further confirmed that X5 decreased significantly in the uncontrolled asthma group ${ }^{[26]}$. Fres also known as resonant frequency refers to the frequency when the elastic recoil of the airways and lungs is equal and opposite to the inertance of the system, that is, the reactance is zero. Moreover, based on the mechanical properties of airways, Fres is the dividing point between large and small airways ${ }^{[24]}$. Our result revealed that Fres had a certain significance in predicting the acute attack of asthma, but there was large heterogeneity $\left(\mathrm{I}^{2}=85.1 \%, \mathrm{p}=0.000\right)$. This may be contributed to the small number of trials and the large age span between the trials. AX means the area under the reactance curve between $5 \mathrm{~Hz}$ (X5) and the Fres value, similar to $\mathrm{X} 5$, which also can provide information about distal airway obstruction ${ }^{[27]}$. Our research found a significant correlation between AX and acute asthma.

Peripheral airways have much smaller lumina than central (large) airways, and inflammation/edema in the walls of peripheral airways can be expected to have a proportionately larger effect on lumen size than inflammation/edema in larger airways. The above indicators reveal that peripheral airway impairment may be associated with uncontrolled asthma. Besides, previous studies have also reported that peripheral airway impairment is clinically related to asthma exacerbation, uncontrolled asthma, loss of control, and asthma severity ${ }^{[22,23]}$. However, our study did not find the role of the R5-20 indicator in predicting the loss of asthma control.R5-20 refers to the resistance of the peripheral airways, which was also inconsistent with previous research. This may be related to the age and height of the population included in the study. When the peripheral airway was obstructed, R5 was significantly elevated and R20 was not changed. However, R5 decreased linearly with the growth of height ${ }^{[28]}$.

Our meta-analysis had some limits. First, the severity of asthma

exacerbations or uncontrolled asthma and baseline treatment varied from study to study, which may affect the results. In addition, other factors like race, age, sex, height can also bring out the heterogeneity. These indicate that a large number of randomized trials are still needed to confirm the potential relationship between IOS parameters and acute attack of asthma. Our research also had some advantages. For instance, it is the first systematic review and meta-analysis about the predictive value of the IOS common parameter in asthma exacerbations. And all trials were of high quality.

\section{Conclusion:}

Overall, our results suggested that R5, X5, AX, Fres may be able to predict acute attack or loss of control of asthma, while R20, R5-20 could not. Besides, our research further demonstrated that peripheral airway injury had a good correlation with asthma exacerbations. It may show that in clinical work, the role of peripheral airway injury should be recognized, and timely identification and intervention should be made to reduce the frequency of acute asthma attacks.

\section{CONFLICT OF INTERESTS}

The authors declare that there are no conflict of interest.

\section{References}

[1] Forno E, Celedón JC. Predicting asthma exacerbations in children. Curr Opin Pulm Med. 2012. 18(1): 63-9.

[2] Wu AC, Tantisira K, Li L, et al. Predictors of symptoms are different from predictors of severe exacerbations from asthma in children. Chest. 2011. 140(1): 100-107.

[3] Covar RA, Szefler SJ, Zeiger RS, et al. Factors associated with asthma exacerbations during a long-term clinical trial of controller medications in children. J Allergy Clin Immunol. 2008. 122(4): 741-747.e4.

[4] Bateman ED, Hurd SS, Barnes PJ, et al. Global strategy for asthma management and prevention: GINA executive summary. Eur Respir J. 2008. 31(1): 143-78.

[5] Dawman L, Mukherjee A, Sethi T, Agrawal A, Kabra SK, Lodha R. Role of Impulse Oscillometry in Assessing Asthma Control in Children. Indian Pediatr. 2020. 57(2): 119-123. 
[6] Bisgaard H, Klug B. Lung function measurement in awake young children. Eur Respir J. 1995. 8(12): 2067-75.

[7] Larsen GL, Morgan W, Heldt GP, et al. Impulse oscillometry versus spirometry in a long-term study of controller therapy for pediatric asthma. J Allergy Clin Immunol. 2009. 123(4): 861-7.e1.

[8] Song TW, Kim KW, Kim ES, Park JW, Sohn MH, Kim KE. Utility of impulse oscillometry in young children with asthma. Pediatr Allergy Immunol. 2008. 19(8): 763-8.

[9] Moher D, Liberati A, Tetzlaff J, Altman DG, PRISMA Group. Preferred reporting items for systematic reviews and meta-analyses: the PRISMA statement. Ann Intern Med. 2009. 151(4): 264-9, W64.

[10] Higgins JP, Thompson SG. Quantifying heterogeneity in a meta-analysis. Stat Med. 2002. 21(11): 153958.

[11] Higgins JP, Thompson SG, Deeks JJ, Altman DG. Measuring inconsistency in meta-analyses. BMJ. 2003. 327(7414): 557-60.

[12] Bax L, Ikeda N, Fukui N, Yaju Y, Tsuruta H, Moons KG. More than numbers: the power of graphs in meta-analysis. Am J Epidemiol. 2009. 169(2): 249-55.

[13] Begg CB, Mazumdar M. Operating characteristics of a rank correlation test for publication bias. Biometrics. 1994. 50(4): 1088-101.

[14] Egger M, Davey Smith G, Schneider M, Minder C. Bias in meta-analysis detected by a simple, graphical test. BMJ. 1997. 315(7109): 629-34.

[15] Batmaz SB, Kuyucu S, Arıkoglu T, Tezol O, Aydogdu A. Impulse oscillometry in acute and stable asthmatic children: a comparison with spirometry. J Asthma. 2016. 53(2): 179-86.

[16] Schulze J, Biedebach S, Christmann M, Herrmann E, Voss S, Zielen S. Impulse Oscillometry as a Predictor of Asthma Exacerbations in Young Children. Respiration. 2016. 91(2): 107-14.

[17] Zeng J, Chen Z, Hu Y, Hu Q, Zhong S, Liao W. Asthma control in preschool children with small airway function as measured by IOS and fractional exhaled nitric oxide. Respir Med. 2018. 145: 8-13.

[18] Tirakitsoontorn P, Crookes M, Fregeau W, et al. Recognition of the peripheral airway impairment phenotype in children with well-controlled asthma. Ann Allergy Asthma Immunol. 2018. 121(6): 692-698.

[19] Smith CJ, Spaeder MC, Sorkness RL, Teague WG. Disparate diagnostic accuracy of lung function tests as predictors of poor asthma control in children. J Asthma. 2020. 57(3): 327-334.

[20] Zheng S, Hu Y, Chen Z, Wang M, Liao W. Predicting asthma exacerbation by impulse oscillometry evaluation of small airway function and fractional exhaled nitric oxide in preschool children. Pediatr Pulmonol. 2020. 55(7): 1601-1607.

[21] McGeachie MJ, Yates KP, Zhou X, et al. Patterns of Growth and Decline in Lung Function in Persistent Childhood Asthma. N Engl J Med. 2016. 374(19): 1842-1852.

[22] Shi Y, Aledia AS, Tatavoosian AV, Vijayalakshmi S, Galant SP, George SC. Relating small airways to asthma control by using impulse oscillometry in children. J Allergy Clin Immunol. 2012. 129(3): 671-8.

[23] Shi Y, Aledia AS, Galant SP, George SC. Peripheral airway impairment measured by oscillometry predicts loss of asthma control in children. J Allergy Clin Immunol. 2013. 131(3): 718-23.

[24] McDowell KM. Recent Diagnosis Techniques in Pediatric Asthma: Impulse Oscillometry in Preschool Asthma and Use of Exhaled Nitric Oxide. Immunol Allergy Clin North Am. 2019. 39(2): 205-219.

[25] Bickel S, Popler J, Lesnick B, Eid N. Impulse oscillometry: interpretation and practical applications. Chest. 2014. 146(3): 841-847. 
[26] Galant SP, Fregeau W, Pabelonio N, Morphew T, Tirakitsoontorn P. Standardized IOS Reference Values Define Peripheral Airway Impairment-Associated Uncontrolled Asthma Risk Across Ethnicity in Children. J Allergy Clin Immunol Pract. 2020 .

[27] Galant SP, Komarow HD, Shin HW, Siddiqui S, Lipworth BJ. The case for impulse oscillometry in the management of asthma in children and adults. Ann Allergy Asthma Immunol. 2017. 118(6): 664-671.

[28] Dencker M, Malmberg LP, Valind S, et al. Reference values for respiratory system impedance by using impulse oscillometry in children aged 2-11 years. Clin Physiol Funct Imaging. 2006. 26(4): 247-50.

\section{Hosted file}

fig1.docx available at https://authorea.com/users/349173/articles/474258-the-predictivevalue-of-impulse-oscillometry-for-asthma-exacerbations-in-childhood-a-systematic-reviewand-meta-analyses

\section{Hosted file}

fig2.docx available at https://authorea.com/users/349173/articles/474258-the-predictivevalue-of-impulse-oscillometry-for-asthma-exacerbations-in-childhood-a-systematic-reviewand-meta-analyses

\section{Hosted file}

Fig.3.docx available at https://authorea.com/users/349173/articles/474258-the-predictivevalue-of-impulse-oscillometry-for-asthma-exacerbations-in-childhood-a-systematic-reviewand-meta-analyses

\section{Hosted file}

table1.docx available at https://authorea.com/users/349173/articles/474258-the-predictivevalue-of-impulse-oscillometry-for-asthma-exacerbations-in-childhood-a-systematic-reviewand-meta-analyses 